NASA/TM-2002-211886

\title{
Flywheel Magnetic Suspension Developments
}

Alan Palazzolo, Andrew Kenny, Shuliang Lei, Yeonkyu Kim, Guangyoung Sun, ChonHee Chon, Randy Tucker, Jason Preuss, Ming Li, Thomas Minihan, Curtiss Sifford, Erwin Thomas, Mohammad Bhuiyan, and Karthik Ganesan

Texas A\&M University, College Station, Texas

Andrew Provenza

Glenn Research Center, Cleveland, Ohio

Albert Kascak and Gerald Montague

U.S. Army Research Laboratory, Glenn Research Center, Cleveland, Ohio 
NASA/TM-2002-211886

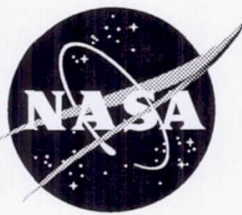

\section{Flywheel Magnetic Suspension Developments}

Alan Palazzolo, Andrew Kenny, Shuliang Lei, Yeonkyu Kim, Guangyoung Sun, ChonHee Chon, Randy Tucker, Jason Preuss, Ming Li, Thomas Minihan, Curtiss Sifford, Erwin Thomas, Mohammad Bhuiyan, and Karthik Ganesan

Texas A\&M University, College Station, Texas

Andrew Provenza

Glenn Research Center, Cleveland, Ohio

Albert Kascak and Gerald Montague

U.S. Army Research Laboratory, Glenn Research Center, Cleveland, Ohio

Prepared for the

37th Intersociety Energy Conversion Engineering Conference sponsored by the Institute of Electrical and Electronics Engineers, Electron Devices Society Washington, DC, July 28-August 2, 2002

National Aeronautics and

Space Administration

Glenn Research Center 


\section{Acknowledgments}

The authors wish to acknowledge the financial and technical support provided by NASA Glenn via programs NRA-99-OSS-05 and NRA-GRC-99-02, and by the Texas A\&M Center for Space Power. In particular the following individuals have provided expert technical and managerial support for this project: Kerry McLallin,

Raymond Beach, Andrew Provenza, Dr. Gerald Brown, Gerald Montague, Ralph Jansen, and Pete Kascak of NASA Glenn; Al Federici, Rex Keeney, and Bob Johnson of U.S. Flywheel Systems; and Dr. Dwight Swett, John Blanche, and Martin Beck of Optimal Energy Systems. We acknowledge and applaud their efforts.

Trade names or manufacturers' names are used in this report for identification only. This usage does not constitute an official endorsement, either expressed or implied, by the National Aeronautics and Space Administration.

Available from

NASA Center for Aerospace Information 7121 Standard Drive Hanover, MD 21076
National Technical Information Service 5285 Port Royal Road Springfield, VA 22100 
Since its founding, NASA has been dedicated to the advancement of aeronautics and space science. The NASA Scientific and Technical Information (STI) Program Office plays a key part in helping NASA maintain this important role.

The NASA STI Program Office is operated by Langley Research Center, the Lead Center for NASA's scientific and technical information. The NASA STI Program Office provides access to the NASA STI Database, the largest collection of aeronautical and space science STI in the world. The Program Office is also NASA's institutional mechanism for disseminating the results of its research and development activities. These results are published by NASA in the NASA STI Report Series, which includes the following report types:

- TECHNICAL PUBLICATION. Reports of completed research or a major significant phase of research that present the results of NASA programs and include extensive data or theoretical analysis. Includes compilations of significant scientific and technical data and information deemed to be of continuing reference value. NASA's counterpart of peerreviewed formal professional papers but has less stringent limitations on manuscript length and extent of graphic presentations.

- TECHNICAL MEMORANDUM. Scientific and technical findings that are preliminary or of specialized interest, e.g., quick release reports, working papers, and bibliographies that contain minimal annotation. Does not contain extensive analysis.

- CONTRACTOR REPORT. Scientific and technical findings by NASA-sponsored contractors and grantees.
- CONFERENCE PUBLICATION. Collected papers from scientific and technical conferences, symposia, seminars, or other meetings sponsored or cosponsored by NASA.

- SPECIAL PUBLICATION. Scientific, technical, or historical information from NASA programs, projects, and missions, often concerned with subjects having substantial public interest.

- TECHNICAL TRANSLATION. Englishlanguage translations of foreign scientific and technical material pertinent to NASA's mission.

Specialized services that complement the STI Program Office's diverse offerings include creating custom thesauri, building customized databases, organizing and publishing research results ... even providing videos.

For more information about the NASA STI Program Office, see the following:

- Access the NASA STI Program Home Page at http://www.sti.nasa.gov

- E-mail your question via the Internet to help@sti.nasa.gov

- Fax your question to the NASA Access Help Desk at 301-621-0134

- Telephone the NASA Access Help Desk at 301-621-0390

- Write to: NASA Access Help Desk NASA Center for AeroSpace Information 7121 Standard Drive Hanover, MD 21076 


\title{
FLYWHEEL MAGNETIC SUSPENSION DEVELOPMENTS
}

\author{
Alan Palazzolo, Andrew Kenny, Shuliang Lei, Yeonkyu Kim, Guangyoung Sun, \\ ChonHee Chon, Randy Tucker, Jason Preuss, Ming Li, Thomas \\ Minihan Curtiss Sifford, Erwin Thomas, Mohammad Bhuiyan, Karthik Ganesan \\ Texas A\&M Mechanical Engineering \\ College Station, Texas 77843-3123
}

\author{
Andrew Provenza \\ National Aeronautics and Space Administration \\ Glenn Research Center \\ Cleveland, Ohio 44135
}

\author{
Albert Kascak and Gerald Montague \\ U.S. Army Research Laboratory \\ Glenn Research Center \\ Cleveland, Ohio 44135
}

\begin{abstract}
The paper provides an overview of many areas of the flywheel magnetic suspension (MS) R\&D being performed at the Texas A\&M Vibration Control and Electromechanics Lab (TAMU-VCEL). This includes system response prediction, actuator optimization and redundancy, controller realizations and stages, sensor enhancements and backup bearing reliability.

\section{INTRODUCTION}

In 1997 the VCEL was tasked by NASA to develop a robust controller for magnetic suspension positioning of a 400 watt-hour flywheel battery spinning at $40,000 \mathrm{rpm}$. This effort resulted in a new approach to magnetic suspension control that has now been awarded a U.S. patent, and was subsequently utilized in the successful magnetic suspension of a $60,000 \mathrm{rpm}$ flywheel. Although this accomplishment was remarkable, many other related areas require similar levels of innovation for practical implementation of a magnetic suspension for satellite and ISS (International Space Station) service. These areas include:

- lowering power loss due to eddy currents, hysteresis and ohmic losses in the magnetic bearing actuator

- providing for redundant (fail safe) operation

- minimizing susceptibility of position feedback sensors to switching power amplifier and adjacent sensor EMI, and to out-of-roundness and non-uniformity of the spinning target for the sensor.
\end{abstract}

- providing reliable means to protect the magnetic bearing actuators while operating the shaft on mechanical "catcher" bearings

- developing magnetic suspension control strategies that are effective in the presence of gyroscopic moments due to precessions applied to the flywheel housing for satellite attitude control service, i.e. a gyrostat.

- developing radiation-hardened hardware for controller realization

- developing effective means of thermal management for stationary and rotating subsystems

- development of an expert system for detecting and correcting magnetic suspension anomalies and/or alerting the operators of an impending mal-function

- development of a new generation of magnetic suspension and rotordynamic design software including GUI's for ease of use by commercial flywheel vendors and NASA.

The remainder of this manuscript provides discussions of the TAMU-VCEL's response to these needs.

\section{R\&D AREAS}

\section{System Simulation and MS Control Laws}

Classical rotordynamics relies on accurate models of passive components to describe the interaction forces between a spinning shaft and its suspension, that typically consists of ball, oil film, or foil bearings and seals. These components lack provision to adapt their force-based responses to the shaft's lateral and axial motion. In comparison to this, the MS may be 
designed to optimally stabilize the shaft's motion with minimum power loss. This benefit requires careful selection of a feedback control law that accounts for not only the structural responses of the shaft and flywheel housing but also of the sensor, power amplifier, MS actuator and controller $1 / 0$ related dynamics. Thus the system model includes, structural, magnetic, electrical and optical (sensor) dynamics. For this reason classical "rotor" modes become influenced by all of the feedback system and structural dynamics.

Figure 1 shows a model of a flywheel battery whose housing is forced to precess by a motor, for the purpose of producing attitude control torques on a satellite. Table 1 shows the model parameter values. Figure 2 shows the response of the rotor to an imposed 11. degree/sec precession of the flywheel housing. The results show the shaft being forced into the catcher bearing by the gyroscopic torque and re-levitating when the imposed precession is removed. The MS control law typically has the stagetype structure shown in figure 3 .

The pre-filtering stage is for anti-aliasing of the AVD operation and the exit filtering is to smooth the D/A output waveform. The input and output end coordinate transforms change the shaft positions and output force commands into forms that are required for the control strategy, and for the specific locations and directions of the force actuators, respectively. An example of the input transform is transformation from physical to modal coordinates. An example of the output transform is transformation of a desired control moment into the two forces of a couple. The "Digital Filters" stage is the heart of the controller and represents the central strategy of the control law, whether minimizing response to disturbance, achieving maximum stability, providing the highest efficiency or some combination of all of the above. This stage may be based on a state space or modal coordinate control strategy. Due to memory and speed limitations on rad-hardened controllers hardware, it is generally better to simplify (reduce the order of) the digital filter, while maintaining good stability, disturbance rejection and efficiency. The VCEL control strategy employs a unique extension of the nutation and precessional mode control laws presented by Ahrens $(1,2)$ and Okada (3), and results in significant reduction in runout and noise related voltages and currents. This approach is described in Palazzolo, et al. (4) and has been successfully employed with rigid and flexible hub flywheel rotors.

The feedback gain stage in figure 3 is utilized to optimize the control law, by on-site corrections for parameter uncertainties in the model. The "notch filter" stage in figure 3 provides a means to block the feedback of specific components of the sensor outputs. For instance shaft runout creates a false vibration so if conditions demand it, the runout components should be rejected from the feedback path.
Development of the control law requires an accurate model of all components in the system. This proceeds by building flexible shaft and housing models with finite elements, measuring transfer functions of sensor, controllers, power amplifiers and MS actuators, and assembling all feedback related states into a total system model.

\section{Controller Hardware}

The interdependence of the controller hardware and system simulation model becomes clear through considering

- the hardware is based on its effectiveness as demonstrated in the simulation model

- $\quad$ the algorithm must fit (execute) in the memory and speed limits of the controller board, i.e. each stage of a control takes execution time and the control algorithm programmed into it, therefore the entire stream of control actions must occur in less than one time sample. In addition, $1 / O$ filters for anti-aliasing and smoothing must be accounted for in the control law design.

The VCEL has employed the following digital signal processors (DSP) for MS control:

(1) Innovative Integration SB32-50 Mhz processor speed

(2) Innovative Integration SB67-150 Mhz processor speed

These DSP's provide versatility for developing and testing control algorithms and fine tuning them "on the fly" during actual operation of the flywheel. Their limitation is the risk incurred by employing non-rad hardened equipment in a space environment. The scarcity of high speed rad-hardened controller hardware has motivated the VCEL's efforts to develop non-DSP means to realize the controller algorithms. The three approaches being developed are:

- complete analog realization

- Field Programmable Gate Array (FPGA) based realization

- hybrid analog/FPGA realization

These approaches employ existing COTS radhardened devices. A challenge encountered is to provide the required shaft spin speed dependent control logic with analog or FPGA circuitry. Significant progress has been made in this area and added benefits have been discovered such as virtually zero "processing" time with analog circuitry.

\section{Shaft Position Sensors}

The good news about shaft sensors whether reluctance, eddy current, capacitance or optical is their generally high bandwidth. This is desirable in the closed loop control to improve phase margins for stability. The challenges for sensors are:

(a) high susceptibility to EMI from switching power amplifiers, except for optical sensors

(b) high susceptibility to shaft surface imperfections and non-uniformity around the 
circumference of the shaft at the sensor locations, especially for optical sensors

(c) DC drift due to thermal environment changes

Tests at the VCEL shows that an eddy current position sensor near to a coil that is suddenly powered up with a PWM power amplifier (P.A) produces an output noise floor that suddenly jumps by about $30 \mathrm{~dB}$. This phenomena may cause high current slew rate commands that saturate the power amplifiers. One fix for this is post filtering the P.A. output.

Optical sensors perform best with a highly polished target requiring a 5-10 micron uniformly polished surface. This surface quality is difficult to achieve typically yielding large runout. Our present recommendation is to utilize eddy current sensors and P.A. post filters for position feedback since they exhibit the least susceptibility to noise and shaft runout. A sensor rig as shown in figure 3 will be utilized for sensor development.

\section{Fault Tolerance Actuators}

Backup systems are very important for space application of flywheel batteries. Fault tolerance of critical components can provide a far less expensive substitute for entire module backup. Magnetic bearing actuators may experience coil or power amplifier failures, which would normally cause the shaft suspension to fail leading to operation on the mechanical catcher bearings. Fault tolerance actuators instead continue to provide uninterrupted levitation forces in spite of coil failures. This is accomplished for heteropolar MB's as described in $\mathrm{Na}$ and Palazzolo $(5,6)$. Recent efforts in the VCEL have shown similar fault tolerant capabilities for homopolar magnetic bearings.

The six pole homopolar MB shown in figure 4 has shown an ability to produce invariant forces even with up to 4 of the poles failed. This MB is presently being built and its capabilities will be tested shortly.

\section{Thermal Modeling}

Limiting hot spot temperatures on the rotor and stator is a key objective of MS design for flywheel batteries. Losses at the magnetic bearings provide heat inputs to the magnetically suspended rotor, which cause high temperatures due to the vacuum environment.

Two-dimensional and 3D heat transfer models of the MB's and rotor provide valuable guidance for reducing rotor and stators hot spot temperatures. Figure 5 and 6 show a 3D thermal model of the rotor and $2 \mathrm{D}$ model of the $\mathrm{MB}$, respectively. A practical application of the thermal model is its ability to identify tolerable levels of $\mathrm{MB}$ power loss in terms of the resulting temperatures on the shaft, hub and composite rim. For example, figure 5 is the steady state temperature response of a flywheel rotor due to 5 watt inputs at each MB.

\section{Auxiliary B (Catcher Bearings)}

The intrinsic redundancy in the MS is the mechanical backup bearings, which catch and suspend the shaft in the event of a complete MS failure. Operation on the catcher bearings (CB) excites transient vibration response that may be benign or severe leading to failure of the CB's and possibly the MB's. It follows that careful design of the CB's and their support system is a critical step in the MS design process. VCEL developed codes are utilized to predict forces, temperature changes, internal clearance changes and motions for ball bearings utilized as CB's. Figure 7 represents a simulation model for a flywheel battery that include two catcher bearings (CB1 and $\mathrm{CB} 2$ ). Figure 8 illustrates the detailed CB model that includes nonlinear, speed dependent stiffness, heat sources from lubricants friction and from sliding contact of the shaft on the bearing's inner race, and a squeeze film damper. The MS power-off condition response of the shaft is shown in figure 9. Note that the vibrations indicate a short period of high frequency backward whirling at 0.2 seconds after MS "power-off". This is followed by a more benign low frequency bouncing of the rotor on the CB's.

\section{Drag Torque Test Rig.}

Successful magnetic suspension of a flywheel battery requires that its magnetic bearing, eddy current induced drag torques are very small in order to improve efficiency and present overheating of the rotor. A specialized test rig for measuring $M B$ drag torques in the equivalent power loss range of $2-5$ watts at $60,000 \mathrm{rpm}$ is nearing completion in the VCEL (figure 10). This will provide a means to measure the effects of modifications on power loss in the search for ultra-low loss MB's and motor/ generators. The rig will also provide a means to improve the accuracy of modeling approaches for MB hysteresis and eddy current losses.

\section{Pre-Load Loss Monitor Test Rig.}

Loss of radial preload between the concentric rings of a composite rim flywheel may cause harmful effects on its operation. The University of Texas at Austin-Center for Electromechanics have developed a means to indicate inter-ring radial preload loss. Figure 11 depicts a soon to be completed VCEL test rig which will be utilized to determine if the magnetic suspension's position and current signals provide reliable detection of the UTA-CEM preload-loss effect.

\section{MS Expert System (ES)}

The MS may operate more reliably and efficiently with an expert system to adapt it to anomaly occurrences and operating conditions (OC). Some OC's include host rocket launch, battery mode, attitude control mode, facing sun or eclipsed by sun low speed or high speed, etc. The ES adapts the MS controller to varying degrees of these operating conditions via a fuzzy logic constructed rule base. In addition the ES rule base is developed to detect 
anomalies and if possible mitigate their effects. Figure 12 shows a typical LabView based panel for the ES.

\section{SUMMARY}

Flywheels for energy storage (batteries) and attitude control promise significant efficiency and environmental benefits. Magnetic suspensions significantly enhance these benefits. The TAMUVCEL is presently leading efforts to optimize design of the Flywheel MS's via the tasks described herein.

\section{REFERENCES}

(1) Ahrens, M., et al., "Performance of a Magnetically Suspended Flywheel Energy Storage Device," IEEE Transactions on Control Systems Technology, Vol. 4; pp 494-502, Sept. 1996.

(2) Ahrens, M., et al., "Design of a Magnetically Suspended Flywheel Energy Storage Device," Fourth International Symposium on Magnetic Bearings, pp 553-558, Aug. 1994.

(3) Okada, Y., et al., "Cross Feedback Stabilization of the Digitally Controlled Magnetic Bearing," Journal of Vibration and Acoustics, Vol. 114, pp 54-59, Jan 1992.

(4) Palazzolo, et al., "System and Method for Controlling Suspension Using a Magnetic Field," U.S. Patent No. 6,323,614 B1, $11 / 27 / 01$

(5) Na, U.J and Palazzolo, A., "Optimized Realization Of Fault Tolerant Heteropolar Magnetic Bearings", ASME J. of Vibrations and Acoustics, Vol.122, No.3, July 2000, pp 209,221.

(6) Na, U.J and Palazzolo,A., "Fault Tolerance of Magnetic Bearings with Material Path Reluctances and Fringe Factors," IEEE Trans. On Magnetics, Vol.30, No.6, Nov. 2000.
TABLE 1.-SIMULATION MODEL PARAMETERS FOR FIGURE 1

\begin{tabular}{|l|l|c|}
\hline \multicolumn{2}{|c|}{ Model Parameter } & Values \\
\hline \multirow{2}{*}{ Weight [lb] } & Flywheel & 28.64 \\
\cline { 2 - 3 } & Housing & 114.55 \\
\hline \multirow{3}{*}{ Ip [lb-in-s $\left.{ }^{2}\right]$} & Flywheel & 193 \\
\cline { 2 - 3 } & Housing & 965 \\
\hline \multirow{3}{*}{ It [lb-in-s $\left.{ }^{2}\right]$} & Flywheel & 233 \\
\cline { 2 - 3 } & Housing & 1165.1 \\
\hline \multirow{4}{*}{ DC Motor } & Kt [lb-in/A] & 5 \\
\cline { 2 - 3 } & Ke [V/rpm] & 5.3944 \\
\cline { 2 - 3 } & L [mH] & 50 \\
\cline { 2 - 3 } & R [Ohm] & 20 \\
\cline { 2 - 3 } & Bandwidth [Hz] & 63.7 \\
\cline { 2 - 3 } & Damping [lb-in-s] & 0.001 \\
\hline \multicolumn{2}{|l|}{ Table 1: (Continued) } & 50 \\
\hline MB Load Capacity [lb] & 10 \\
\hline CB Clearance [mil] & 0.1 \\
\hline CB Friction Coefficient. & 11 \\
\hline $\begin{array}{l}\text { Housing Target } \\
\text { [deg./sec] }\end{array}$ & \\
\hline
\end{tabular}
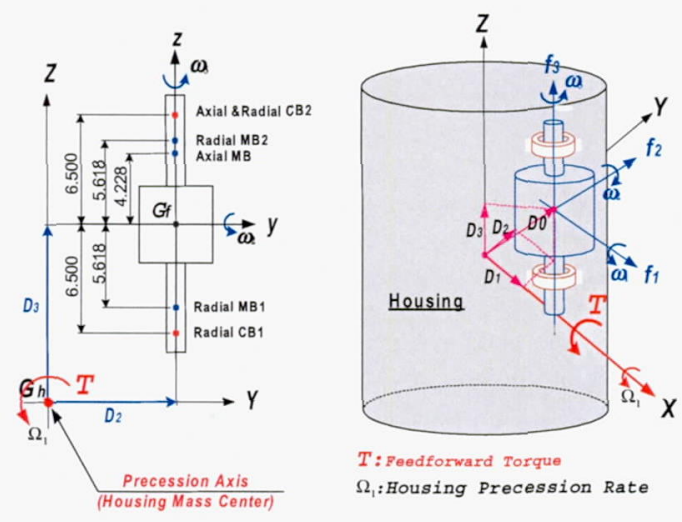

FIGURE 1.-MODEL OF FLYWHEEL FOR COMBINED ENERGY STORAGE/ATTITUDE CONTROL SERVICE. 

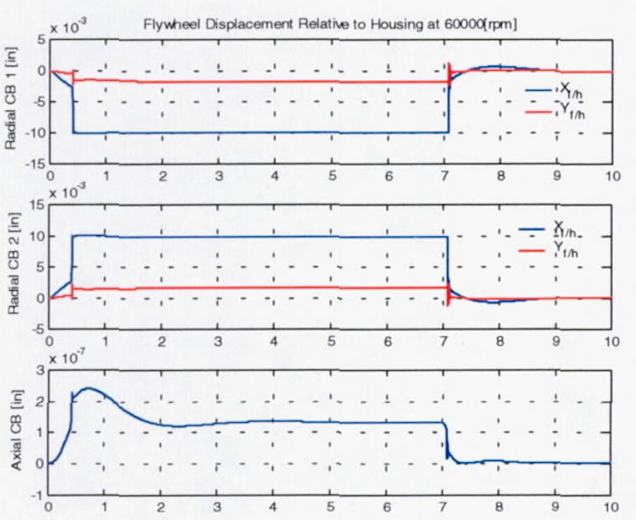

FIGURE 2.-FLYWHEEL DISPLACEMENT RELATIVE TO HOUSING AT CATCHER BEARING LOCATIONS.

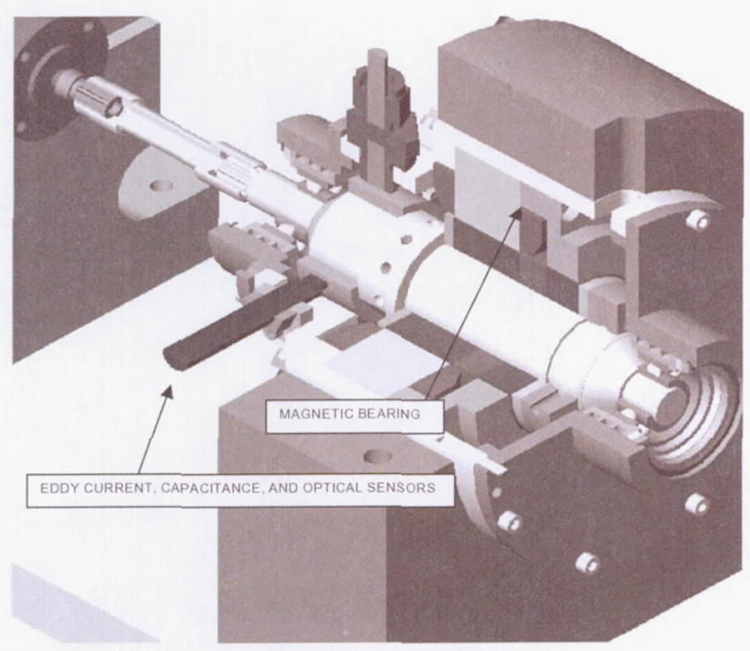

FIGURE 3.-HIGH SPEED $(60,000+$ rpm) TEST RIG FOR POSITION FEEDBACK SENSOR DEVELOPMENT.

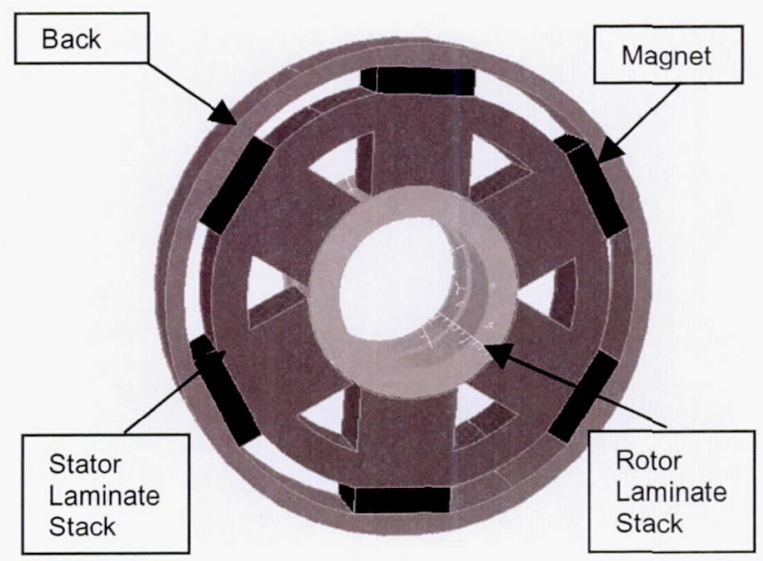

FIGURE 4.-PARTIAL VIEW OF 6 POLE HOMOPOLAR FOR REDUNDANT SERVICE.

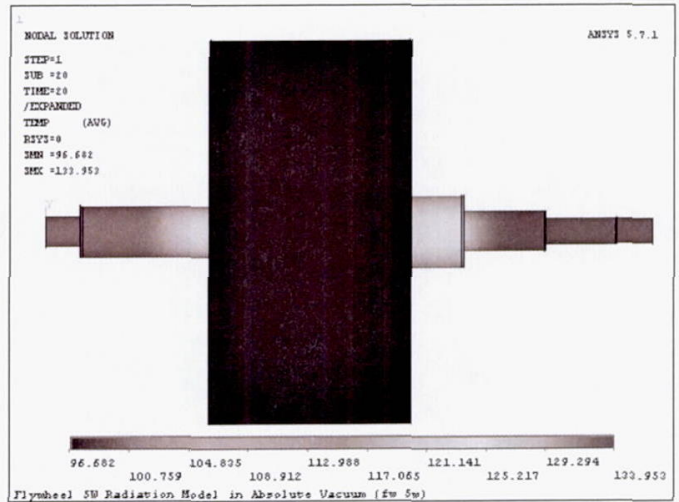

FIGURE 5.-THERMAL MODEL RESULTS FOR A FLYWHEEL WITH MB HEAT SOURCES.

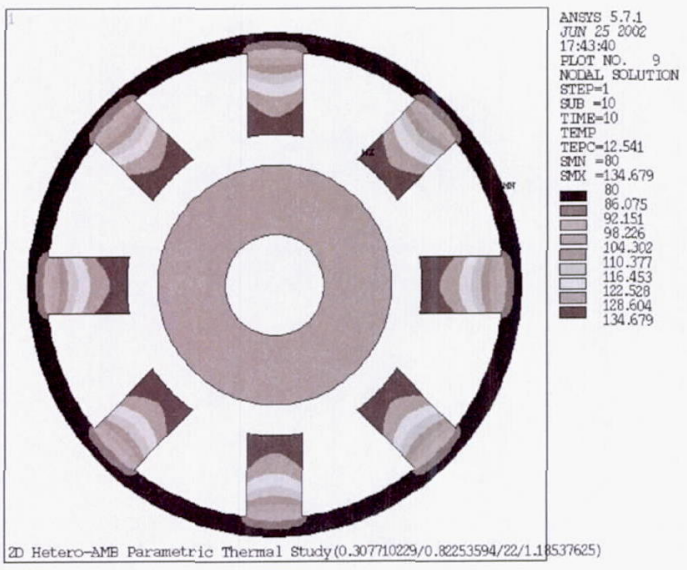

FIGURE 6.-2D THERMAL MODEL OF MAGNETIC BEARING ACTUATOR WITH GAPS INTENTIONALLY ENLARGED. 


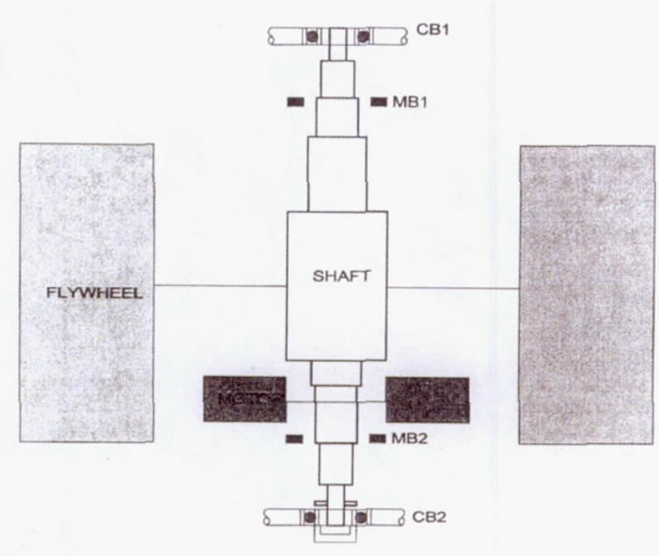

FIGURE 7.-VERTICAL ROTOR SHAFT WITH FLYWHEEL, MOTOR AND MAGNETIC AND CATCHER BEAGINGS.

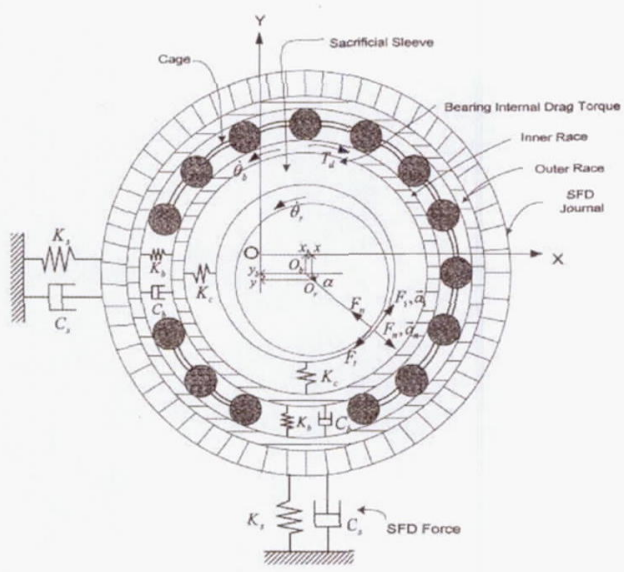

FIGURE 8.-DETAILED CATCHER BEARING MODEL SUPPORTED ON SQUEEZE FILM DAMPER.
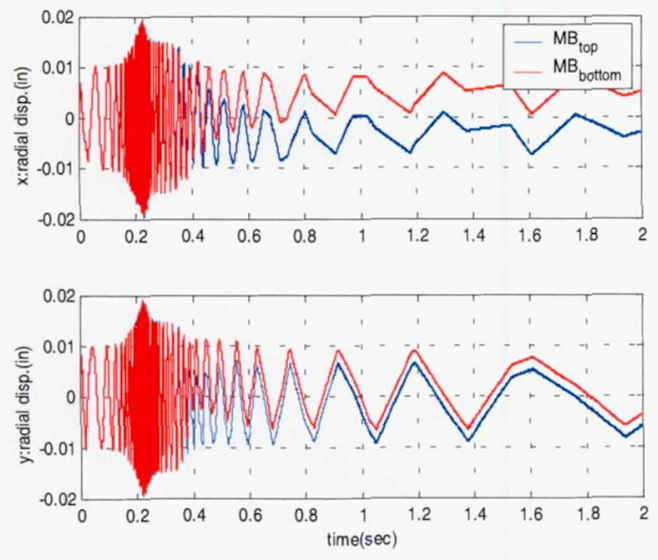

FIGURE 9.--RADIAL DYNAMIC RESPONSE OF THE SHAFT AT MB LOCATIONS.

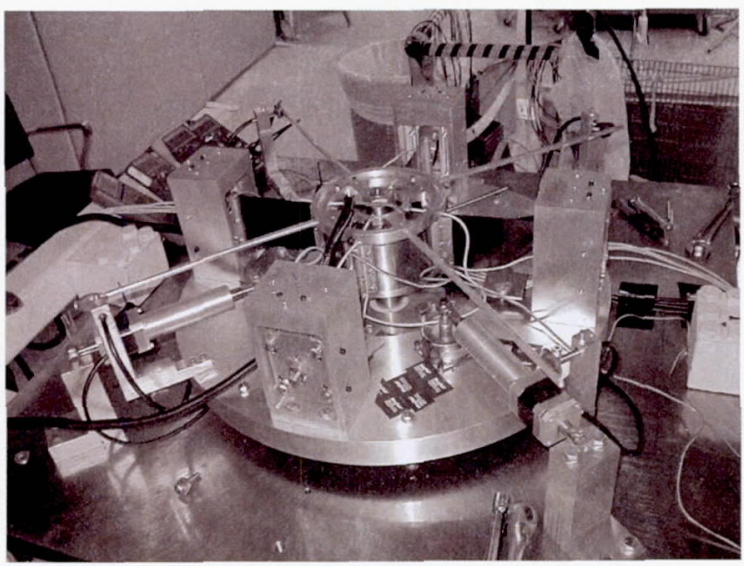

FIGURE 10.- DRAG TORQUE MEASUREMENT TEST FIXTURE.

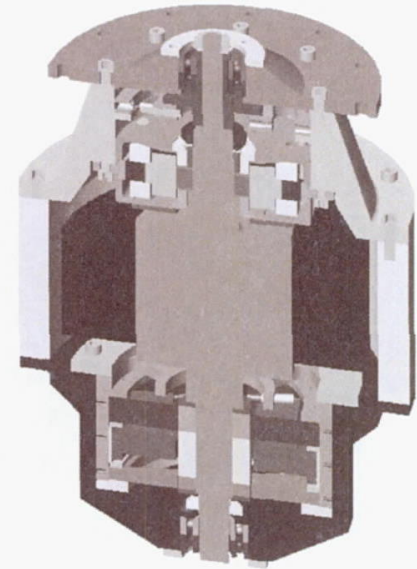

FIGURE 11.-VCEL TEST RIG FOR INDICATING UTA-CEM PRELOAD LOSS MONITOR EFFECT.

\begin{tabular}{|c|c|c|}
\hline \multicolumn{3}{|c|}{ NASA INTELLIGENT CONTROL SYSTEM } \\
\hline $\begin{array}{c}\text { OSP SAMPLE RATE } \\
(H Z)\end{array}$ & SPEED (RPM) 2 & 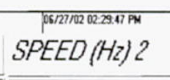 \\
\hline 15000.00 & 18575.85 & 309.60 \\
\hline
\end{tabular}

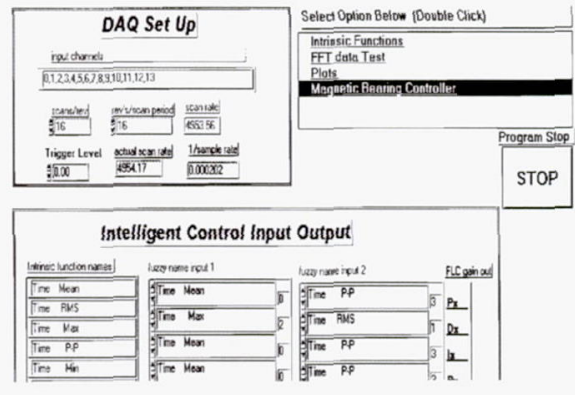

FIGURE 12.-TYPICAL PANEL FOR MAGNETIC SUSPENSION ES. 


\section{REPORT DOCUMENTATION PAGE}

Public reporting burden for this collection of information is estimated to average 1 hour per response, including the time for reviewing instructions, searching existing data sources, gathering and maintaining the data needed, and completing and reviewing the collection of information. Send comments regarding this burden estimate or any other aspect of this collection of information, including suggestions for reducing this burden, to Washington Headquarters Services, Directorate for Information Operations and Repo Davis Highway, Suite 1204, Arlington, VA 22202-4302, and to the Office of Management and Budget, Paperwork Reduction Project (0704-0188), Washington, DC 20503.

\begin{tabular}{|l|l|l}
\hline 1. AGENCY USE ONLY (Leave blank) & $\begin{array}{r}\text { 2. REPORT DATE } \\
\text { September } 2002\end{array}$ & $\begin{array}{r}\text { 3. REPORT TYPE AND DATES COVERED } \\
\text { Technical Memorandum }\end{array}$ \\
\hline
\end{tabular}

\section{TITLE AND SUBTITLE}

5. FUNDING NUMBERS

Flywheel Magnetic Suspension Developments

6. AUTHOR(S)

WU-757-A1-00-00

Alan Palazzolo, Andrew Kenny, Shuliang Lei, Yeonkyu Kim, Guangyoung Sun, ChonHee Chon,

Randy Tucker, Jason Preuss, Ming Li, Thomas Minihan, Curtiss Sifford, Erwin Thomas, Mohammad

Bhuiyan, Karthik Ganesan, Andrew Provenza, Albert Kascak, and Gerald Montague

7. PERFORMING ORGANIZATION NAME(S) AND ADDRESS(ES)

National Aeronautics and Space Administration

John H. Glenn Research Center at Lewis Field

Cleveland, Ohio 44135-3191

8. PERFORMING ORGANIZATION

REPORT NUMBER

E-13568

9. SPONSORING/MONITORING AGENCY NAME(S) AND ADDRESS(ES)

10. SPONSORING/MONITORING

AGENCY REPORT NUMBER

National Aeronautics and Space Administration

Washington, DC 20546-0001

NASA TM-2002-211886

\section{SUPPLEMENTARY NOTES}

Prepared for the 37th Intersociety Energy Conversion Engineering Conference sponsored by the Institute of Electrical and Electronics Engineers,

Electron Devices Society, Washington, DC, July 28-August 2, 2002. Alan Palazzolo, Andrew Kenny, Shuliang Lei, Yeonkyu Kim, Guangyoung Sun,

ChonHee Chon, Randy Tucker, Jason Preuss, Ming Li, Thomas Minihan, Curtiss Sifford, Erwin Thomas, Mohammad Bhuiyan, and Karthik Ganesan,

Texas A\&M University, College Station, Texas 77843-3123; Andrew Provenza, NASA Glenn Research Center; and Albert Kascak and Gerald Montague,

U.S. Army Research Laboratory, NASA Glenn Research Center. Responsible person, Andrew Provenza, organization code 5930, 216-433-6025.

\begin{tabular}{|l|l}
\hline 12a. DISTRIBUTION/AVAILABILITY STATEMENT & 12b. DISTRIBUTION CODE
\end{tabular}

Unclassified - Unlimited

Subject Category: 44

Distribution: Nonstandard

Available electronically at http://gltrs.grc.nasa.gov

This publication is available from the NASA Center for AeroSpace Information, 301-621-0390.

13. ABSTRACT (Maximum 200 words)

The paper provides an overview of many areas of the flywheel magnetic suspension (MS) R\&D being performed at the Texas A\&M Vibration Control and Electromechanics Lab (TAMU-VCEL). This includes system response prediction, actuator optimization and redundancy, controller realizations and stages, sensor enhancements, and backup

bearing reliability.

\section{SUBJECT TERMS}

Flywheel; Magnetic bearing; Magnetic suspension; Energy storage; Attitude control

15. NUMBER OF PAGES

12

16. PRICE CODE

\begin{tabular}{|c|c|c|}
\hline $\begin{array}{c}\text { 17. SECURITY CLASSIFICATION } \\
\text { OF REPORT } \\
\text { Unclassified }\end{array}$ & $\begin{array}{c}\text { 18. SECURITY CLASSIFICATION } \\
\text { OF THIS PAGE } \\
\text { Unclassified }\end{array}$ & $\begin{array}{c}\text { 19. SECURITY CLASSIFICATION } \\
\text { OF ABSTRACT } \\
\text { Unclassified }\end{array}$ \\
\hline
\end{tabular}

